\title{
Endoscopic treatment of vesicoureteric reflux in adults with a neuropathic bladder
}

\author{
SJ Foley, MKM Sheriff and PJR Shah \\ The Spinal Injuries Unit, Royal National Orthopaedic Hospital Trust, Stanmore, UK
}

The injection of submeatal paste to treat vesicoureteric reflux is well documented in paediatric patients but there is little documentation on this treatment for adults, especially with secondary reflux. We present our experience of treatment of five adults with neuropathic bladders, consisting of eight refluxing ureters. $63 \%$ showed complete resolution of reflux and all showed improvement with no complications. The high degree of success, ease of the procedure and the lack of complications suggests that this could be the treatment of choice for adults with a neuropathic bladder and vesicoureteric reflux.

Keywords: vesicoureteric reflux; neuropathic bladder; endoscopic submeatal paste

\section{Introduction}

Vesicoureteric reflux (VUR) in spinal cord injured patients is a major cause of morbidity. Talbot et al found that VUR in spinal cord injury patients after World War II was the commonest cause of hydronephrosis and led to progressive renal deterioration, in the presence of urinary tract infection which is frequently present in spinal injury patients. The exact incidence of VUR in paraplegic patients is unknown. Hutch $^{2}$ found an incidence of $13 \%$ in patients who had been paraplegic for 3 years, and a recent review of 800 patients at Stanmore showed an incidence of $8 \%$. The cause of VUR is also unclear, the high intravesical pressures seem certainly to play a role but are unlikely to be the only cause and there is a small group with VUR and low intravesical pressures. An incompetent vesicoureteric valve permits both the transmission of high intravesical pressures and ascending infection which can lead to hydro-ureter and renal deterioration.

In 1952 Hutch reported success in eight of 11 ureteric reimplantations for VUR in nine paraplegic patients. The various surgical procedures to cure VUR aim to prevent reflux thus protecting the kidneys from the waterhammer effect of higher pressure. Until 1972 , surgery was reserved for patients in whom results of conservative treatment were unsatisfactory but many workers found the results of conservative treatment to be disappointing and encouraged the use of anti-reflux procedures. ${ }^{3}$ The results of the reimplantation of the ureters into thick walled trabeculated neuropathic bladders have been less rewarding than reimplantation of primary VUR so alternative treatments need to be considered.

Correction of VUR by endoscopic injection of Teflon paste was first described by Matovschek ${ }^{4}$ and

Correspondence: SJ Foley its effectiveness confirmed by Puri \& O'Donnell ${ }^{5,6}$ in eight piglets and subsequently 13 girls. Since then the technique has been widely used and a recent 10 year European review ${ }^{7}$ showed that the use of a submucosal injection (STING) to be a safe and effective day case procedure for the treatment of all grades of VUR. Most of these results, however, are on children with primary VUR and little is reported on adults with a neuropathic type of bladder. We report our experience of the treatment of eight refluxing ureters in five patients. Polydimethylsiloxone (Macroplastique) is an injectable, silicone based paste which has been used for performing the STING in a limited number of series ${ }^{8}$ and has been used in four of five patients in this study.

\section{Patients and methods}

Patients with VUR secondary to a neuropathic bladder were included in this study. The age ranges were $16-$ 34 , the causes of the neuropathic bladders were four patients with traumatic spinal injuries and one with spina bifida. All patients with detrusor hyperreflexia were maintained on oxybutanin to lower intravesical pressure. Patients emptied their bladders, to reduce outlet obstruction, either by intermittent self catheterisation (3), or had had sphincter surgery (2). Reflux was bilateral in three patients and unilateral in two and the gradings (according to the international reflux committee) were: three ureters had grade two and five ureters had grade four reflux. Four out of five patients were treated by the same surgeon (PJRS) using Microplastique and one was performed using Teflon.

All of the procedures were performed under a general anaesthetic, although with more experience and the availability of modern flexible equipment it will be possible to perform this technique under a local anaesthetic. Using an aseptic technique the lumen of 
Table 1

\begin{tabular}{|c|c|c|c|c|c|c|c|}
\hline Patient & Age & $\begin{array}{c}\text { Level of } \\
\text { injury }\end{array}$ & $\begin{array}{l}\text { Side and } \\
\text { grade }\end{array}$ & $\begin{array}{c}\text { Sting } \\
\text { material }\end{array}$ & Post op & $\begin{array}{l}\text { Follow up } \\
\text { period }\end{array}$ & $\begin{array}{c}\text { Result } \\
\text { (grade) }\end{array}$ \\
\hline 1 & 23 & L1 & Left: & Bioplast & Well & $14 / 12$ & 0 \\
\hline 2 & 30 & T6 & $\begin{array}{ll}\text { Left: } & 4 \\
\text { Right: } & 4\end{array}$ & Bioplast & Well & 2 yrs & $\begin{array}{l}0 \\
2\end{array}$ \\
\hline 3 & 34 & $\mathrm{~T} 9$ & Right: 4 & Teflon & Well & $5 \mathrm{yrs}$ & 0 \\
\hline 4 & 16 & $\mathrm{~T} 10$ & $\begin{array}{ll}\text { Left: } & 2 \\
\text { Right: } & 4\end{array}$ & Bioplast & Well & $2 \mathrm{yrs}$ & $\begin{array}{l}1 \\
1\end{array}$ \\
\hline 5 & 17 & $\mathrm{C} 7$ & $\begin{array}{ll}\text { Left: } & 2 \\
\text { Right: } & 2\end{array}$ & Bioplast & Well & $2 \mathrm{yrs}$ & $\begin{array}{l}0 \\
0\end{array}$ \\
\hline
\end{tabular}

the endoscopic needle, pre-lubricated and attached to a Macroplastique syringe, was primed. The needle was passed down the instrument channel and under the distal ureter. Between 1-2.5 mls of Macroplastique was injected under the ureteric orifice to change the orifice shape from round to more slit like. The patients were all monitored in the ward overnight and discharged the following day. Follow up was by video urodynamics, the follow up time ranging from 14 months to 5 years.

\section{Results}

The results of treatment are summarized in the Table. Five of the ureters showed complete disappearance of reflux and the remaining three showed an improvement in reflux. All of these were using a single endoscopic injection and further injections could be used to further improve the results. Pre-operatively four patients had recurrent laboratory proven urinary tract infections (UTIs) which resolved post-operatively with only one patient complaining of infective symptoms, but there was no infection evident on laboratory testing. One patient had shown a deterioration in renal function pre-operatively, with a split DTPA scan of Right $39 \%$ and Left $61 \%$ function, but normal GFR, which remained the same after the procedure. One patient continued to show very high intravesical pressures and underwent a Clam Ileocystoplasty to reduce the pressure and had one ureter reimplanted at the same operation.

\section{Discussion}

Our experience of using this technique for the treatment of VUR in patients with a neuropathic bladder is obviously limited in number but our results compare favorably with the results of larger studies performed on patients with primary and secondary VUR where success rates of $50-90 \%$ are quoted. The simplicity of the procedure, high success rate and lack of complications make it a highly acceptable treatment of VUR in those with a neuropathic bladder. The procedure avoids major surgery, takes $15 \mathrm{~min}$ to perform and can be performed as a day patient if desired. Whether renal damage is improved after antireflux procedures is open to debate, ${ }^{3}$ but we believe that with a neuropathic bladder where renal impairment is a known risk, and the patients are more prone to UTIs, an anti-reflux procedure is a rational form of treatment.

The controversy regarding the use of this method of treatment is the worry that injectables such as Teflon migrate, ${ }^{9}$ and this could potentially lead to long term complications. Injectables, mainly Teflon, have been used for over 30 years to treat incontinence, and 10 years to treat VUR and to date no long term complications have been reported. The Macroplastique paste used in the majority of our patients is a biocompatible material which is hoped will overcome the migratory problems due to larger particle size. Animal studies have indicated that this inert resin heals with minimal inflammation, is non-migratory and non-carcinogenic. ${ }^{10}$ More exposure and time will be needed to confirm this, but from our study the surgical outcome compares well with the success rate of larger studies using Teflon.

\section{References}

1 Talbot HS, Bunts RC. Late renal changes in paraplegia: Hydronephrosis due to vesicouretral reflux. J Urol 1949; 61: 810.

2 Hutch JA. Vesicoureteral reflux in the paraplegic, cause and correction. J Urol 1952; 68: 4.

3 De Sy W, Oosterlinch W, Wynuacle JJ. A plea for anti-reflux operations in adults: review of 50 cases. J Urol 1978; 120: 549 551.

4 Matovschek E. Die Behandlung des vesicorenalon Refluxes durch transurethralen Einspritzung von Teflonpaste. Urologe (A) 20: $263-266$.

5 O'Donnell B, Puri P. Treatment of vesicoureteric reflux by endoscopic injection of Teflon. BMJ 1984; 289: 7-9.

6 Puri P, O'Donnell B. Correction of experimentally produced vesicoureteric reflux in the piglet by intravesicle injection of Teflon. $B M J$ 1984; 289: 5-7.

7 Puri P. Ten year experience with subureteric Teflon (polytetrafluoethylene) injection (STING) in the treatment of vesicoureteric reflux. $B J U$ 1995; 75: $126-131$.

8 Preston Smith D, Williams E, Kaplan and Ryoichi Oyasu. Evaluation of polydimethylsiloxone as an alternative in endoscopic treatment of vesico-ureteral reflux. J Urol 1994; 152: $1221-1224$

9 Malizia AA et al. Migration and granulomatous reaction after periurethral injection of Polytef (Teflon). J Am Med Ass 1984; 251: $3277-3281$

10 Henley DR et al. Particulate silicone of use in periurethral injections: a study of local tissue effects and a search for migration. J Urol 1992; 147: 376a. 